\title{
DANIELI'S GREEN STEEL VISION: FIRST STEP TOWARDS ZERO ENERGY FTP AT ABS STEELMAKING PLANT $($ ITALY)*
}

Nicola Santangelo ${ }^{1}$
Luciano Tomadin $^{2}$
Arrigo Bertolissio $^{3}$

\begin{abstract}
The current economic crisis and growing environmental issues have led the steel industry to face the simultaneous effects of low demand and production overcapacity in a globalized steel market, whilst confronting high energy prices and the need to comply with the green economy. Heat Recovery from waste gas of the Electric Arc Furnace (EAF) represents one of the greatest opportunities to reduce the consumption of primary energy and reduce the $\mathrm{CO}_{2}$ emissions in steel industry. The heat of the off-gas, if recovered and converted into electrical power, can make the whole Fumes Treatment Plant autonomous from the electric point of view, thus making it a "Zero-Energy FTP". The concept is to substitute the Cooling Components (Water Cooled Panels and Air Cooler) are substituted with Heat Recovery Components (Hot Water Cooled Panels and Heat Exchanger). The recovered heat can be converted into power by using an Organic Rankine Cycle (ORC) turbine. The heat recovered by the HWCP and the Heat Exchanger is characterized by a variable thermal power, which affects the efficiency of the downstream ORC System. Danieli, in collaboration with the University of Udine, has developed the Thermal Stabilizer Unit (TSU). Danieli has realized the first step towards Zero Energy FTP at ABS steelmaking plant (Italy) by installing a $\mathrm{CHR} \circledast$ - Clean Heat Recovery. This plant has been started up on 17th October 2014. The $\mathrm{HMI}$ of the $\mathrm{CHR} \AA$ is integrated in the $\mathrm{HMI}$ of the furnace, so all the process could be kept under control by the furnace operator. At ABS recovered thermal power reaches $5.5 \mathrm{MW}$. The max power production reached with $\mathrm{CHR}$ plant in ABS (over $1 \mathrm{MW}$ of electric power) consents an annual saving of approx. 500,000 EUR.
\end{abstract}

Keywords: EAF; Clean heat recovery; Energy savings; Green steel; CHR; ORC.

Mechanical Engineering, Executive Vice President, Danieli Environment, Buttrio (UD), Italy.

Mechanical Engineering, Director, Danieli Environment, Buttrio (UD), Italy.

Mechanical Engineering, Executive Technical Manager, Technical Office, Danieli Environment, Buttrio (UD), Italy. 


\section{INTRODUCTION}

The current economic crisis and growing environmental issues have led the steel industry to face the simultaneous effects of low demand and production overcapacity in a globalized steel market, whilst confronting high energy prices and the need to comply with the green economy. In this context, energy efficiency becomes a key objective to gain both cost savings and the reduction of greenhouse gas emission. In particular, heat recovery from waste gas of the electric arc furnace (EAF) represents one of the greatest opportunities to reduce the consumption of primary energy and $\mathrm{CO}_{2}$ emissions in steel industry. It has been estimated that $25 \% \div 30 \%$ of the total energy provided to the steelmaking processes by means electric arc furnace is lost by exhaust gas, named also off-gas or primary fumes. The most common heat recovery systems from off-gas are those that involve the pre-heating of scrap. However, the diffusion of scrap pre-heating systems is limited by economic reasons (i.e. higher scrap cost, additional investment and maintenance cost) and environmental issues (dioxins formation due to contamination of the scrap by organic materials). The modern steel plants can overcome these issues adopting a new design approach, based on the integration between fumes cleaning and heat recovery functions, of the fumes treatment plant (FTP). The heat of the off-gas, if recovered and converted into electrical power, can make the whole fumes treatment plant autonomous from the electric point of view, thus making it a "Zero-Energy FTP". This means that it is possible to avoid the operational costs of the FTP, thus increasing the steelmaking competitiveness and its environmental performance. In order to achieve the "Zero-Energy FTP", it is necessary to overcome the challenging difficulties given by the high variability of off-gas temperature. In the following, the solution developed by Danieli\&C. Spa and University of Udine will be explained and its first realization in the ABS Spa steel plant will be shown.

\section{MATERIAL AND METHODS}

\subsection{Traditional Fumes Treatment Plant}

In traditional fumes treatment plants, represented in Figure 1, in order to protect the downstream filtering systems (axial cyclone and bag filters), the off-gases generated by the EAF are cooled down by a sequence of specific equipment, which are usually in the following order:

- Water cooled panels WCPs (mobile duct, fixed duct, settling chamber panels, water cooled duct WDC);

- Cooler (Natural heat exchanger, forced draft cooler or quenching tower);

- Dilution with secondary fumes.

During the melting of scrap in the EAF, large amounts of combustible gases, such as carbon monoxide, are generated. The high temperatures, caused by the oxidation of these combustible gases, are controlled by introducing a large quantity of dilution air through the gap between elbow and mobile duct. Generally, the fumes have a temperature of $1.200-1.300^{\circ} \mathrm{C}$, which is too high for a simple walled duct. In fact, in traditional design, water-cooled ducts are used to conveying the fumes, while watercooled panels are often used in the settling chamber (which also has a function of post-combustion chamber) instead of refractory-lined walls. The traditional cooling system employs water to absorb heat from the fumes heat, which is then cooled by air cooler. 


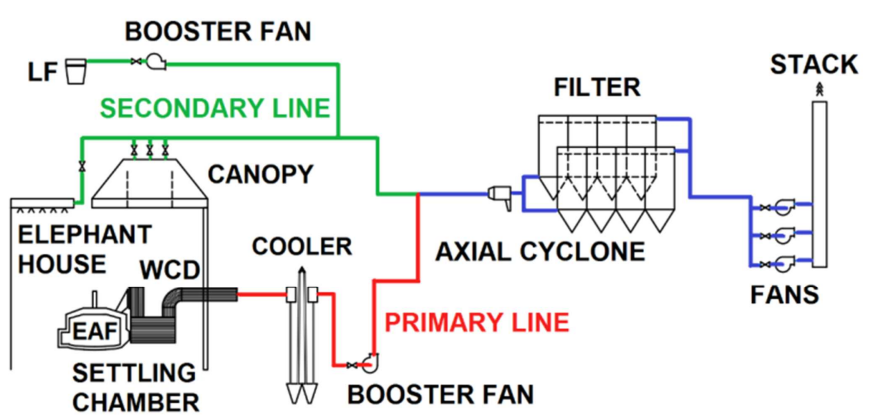

Figure 1: Traditional Fumes Treatment Plant

In Figure 2 is reported the energy balance of a traditional fumes treatment plant. As can be seen, the current configuration of the system employs large amounts of cooling water (about $2.000 \mathrm{~m} 3 / \mathrm{h}$ ) to keep cooled the WCPs, while air cooler dissipates the rest of the off-gas heat. The combination of WCPs and air cooler represents the cooling system of the FTP, which dissipates over the $70 \%$ of the offgas heat. The rest of the off-gas heat goes out through the stack as low enthalpy heat. The cooling system has operative costs associated to the water consumption of evaporative tower and electric consumption associated to the air cooler and watercooling pump. In addition, it is important to note that the sizing of the evaporative tower is based on the thermal power peak absorbed from the off-gas. This means that an high investment cost is required to comply the cooling requirement. However, the most energy intensive equipment of the whole FTP are the fans used to move the off-gas through the system, which usually have an requirement of electric energy per tons of produced steel of about $25 \mathrm{MWhe/t}$. Thus, the large part of the operational costs of a traditional FTP are related to energy consumption of fans.

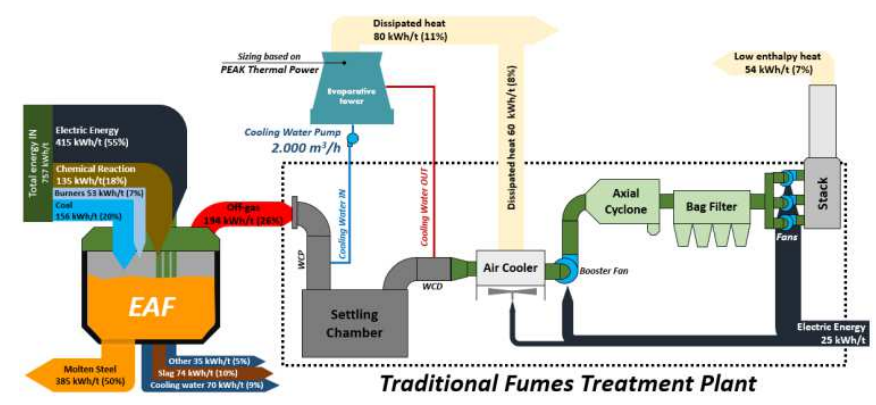

Figure 2: Energy balance of traditional fumes treatment plant

\subsection{Zero energy Fumes Treatement Plant}

In the introduction, it was mentioned that the heat of the off-gas, if recovered and converted into electrical power, could make the whole FTP autonomous from the electric point of view, thus making it a Zero-Energy FTP. Figure 3 shows the energy balance of a Zero-Energy FTP and its main equipment. 


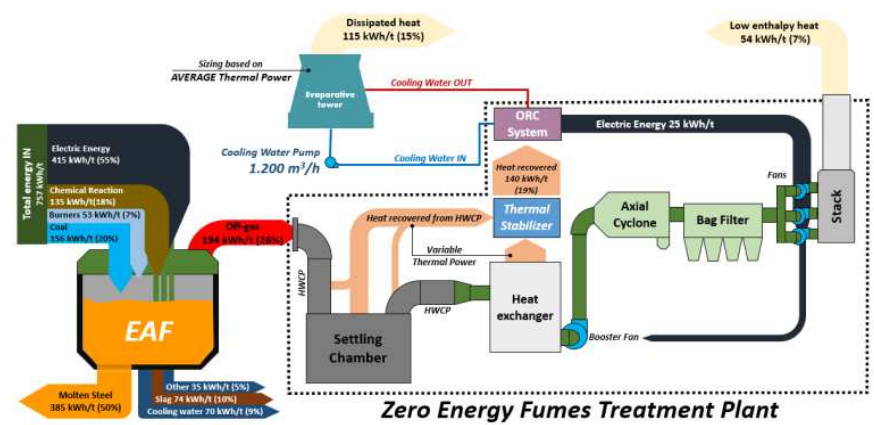

Figure 3: Energy balance of the Zero Energy Fumes Treatment Plant

If the traditional FTP (Figure 2) is compared to the Zero-Energy FTP (Figure 3), it is possible to observe that the cooling components (WCP and air cooler) are substituted with the following heat recovery components:

- Hot Water Cooled Panels (HWCPs): usually, cooling water enters the WCP at a temperature of $30^{\circ} \mathrm{C}$ and it exits at about $50^{\circ} \mathrm{C}$, temperatures that are too low for a convenient heat recovery, except for particular situations, such as the on-site requirement of large quantities of low heat for other industrial uses. The HWCPs are an evolution of the existing WCPs that employ hot pressurized water as heat transfer fluid for energy recovery. The traditional pipe-to-pipe design of WCP is adapted in order to resist to the higher pressure due to the work condition of the hot pressurized water. In addition to the heat recovery function, the use of hot water increase the lifetime of the ducts by reducing corrosion issues and thermal stresses.

- Heat exchanger: it is a heat exchanger expressly designed for heavy work conditions due to the high concentration of dust in the off-gas. This solution allows one to recover the large amount of heat available at relatively low temperatures, not directly recoverable by the HWCP.

The recovered heat can be converted into power by using an Organic Rankine Cycle (ORC) turbine. The operational principle of the ORC is the same as of conventional steam Rankine cycle. The only difference is an organic working fluid with lower boiling temperature is used to the expander (turbine) in ORC instead of water. ORC exhibits great flexibility in utilization of moderate temperature heat source. In fact, ORC can exploit the heat source from solar radiation, geothermal energy, biomass combustion and industrial waste heat. Compared to turbines based on steam Rankine cycle, the advantages of the ORC technology are:

- Simple completely automatic machine;

- No influence on the steel making process;

- No O\&M costs;

- Choice of the right organic fluid to get the best heat recovery and conversion efficiency;

- Direct Coupling with generator and grid;

- Suitable for frequent start\&stop cycles good off-design performances. 

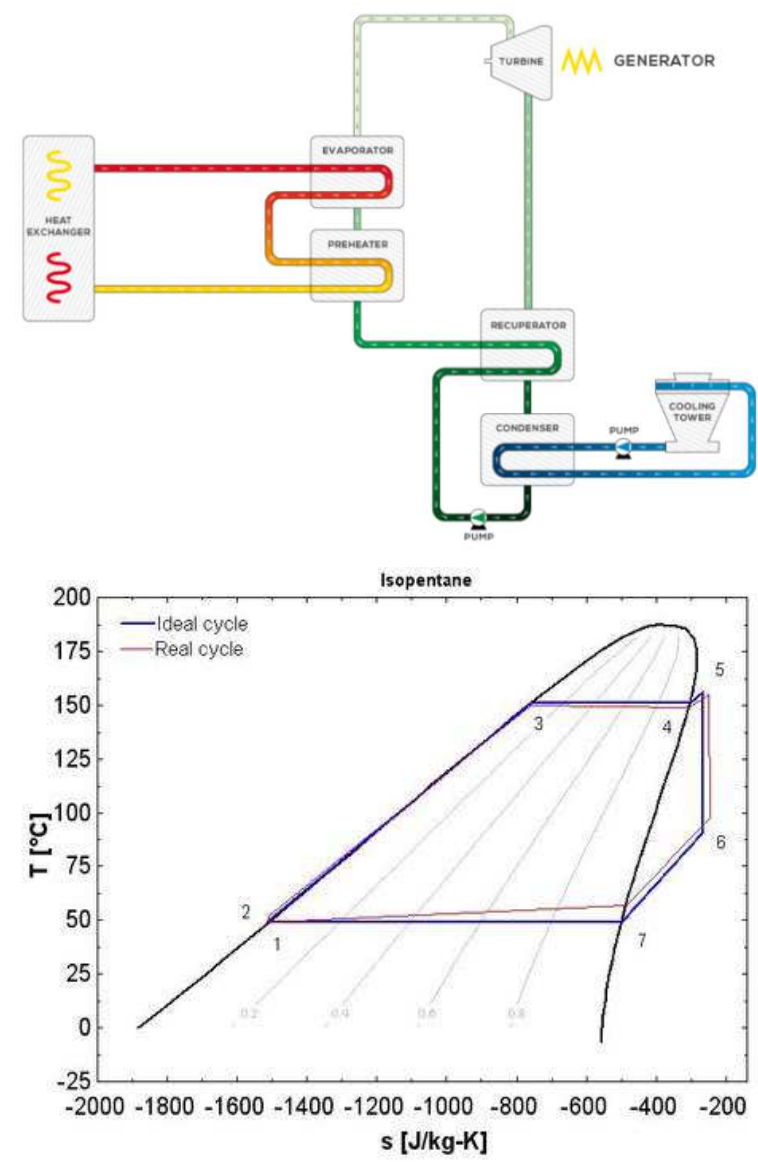

Figure 4: Organic Rankine Cycle

However, the introduction of heat recovery components is not enough to feed the energy conversion system (i.e. ORC System) in an efficient way. In fact, the heat recovered by the HWCP and the heat exchanger is characterized by a variable thermal power, which affects the efficiency of the downstream ORC System. Thus, the development of an innovative equipment able to smooth the thermal power variability is required. Danieli, in collaboration with the University of Udine, has developed the Thermal Stabilizer Unit (TSU), which is shown in Figure 5, as response to this technology requirement. Currently, Thermal Stabilizer Unit is under patent. 

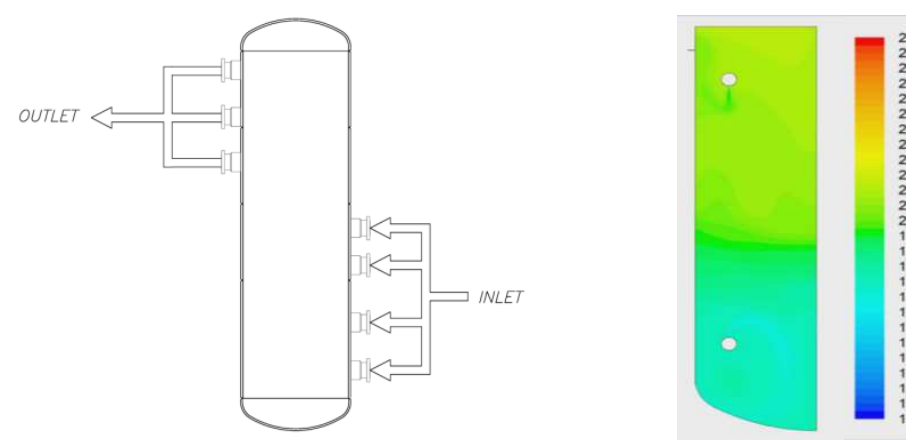

Figure 5: Technical draw (a) and fluid dynamic simulation (b) of the Thermal Stabilizer

The Thermal Stabilizer Unit is an innovative tank of hot pressurized water that acts not only as storage system of thermal energy, but also as smoothing tool of thermal power variability. The innovative design of the thermal stabilizer unit is based on multiple water inlets and outlets, which are specifically positioned to maximize the smoothing effect. Figure 6 shows an example of the Thermal Stabilizer Unit performance; red line represents the water temperature entering the Thermal Stabilizer Unit, while gold line represents the water temperature exiting the Thermal Stabilizer Unit. It is possible to observe that the Thermal Stabilizer Unit reduces the maximum temperature difference from $50^{\circ} \mathrm{C}$ at system inlet to $10^{\circ} \mathrm{C}$ at system outlet.

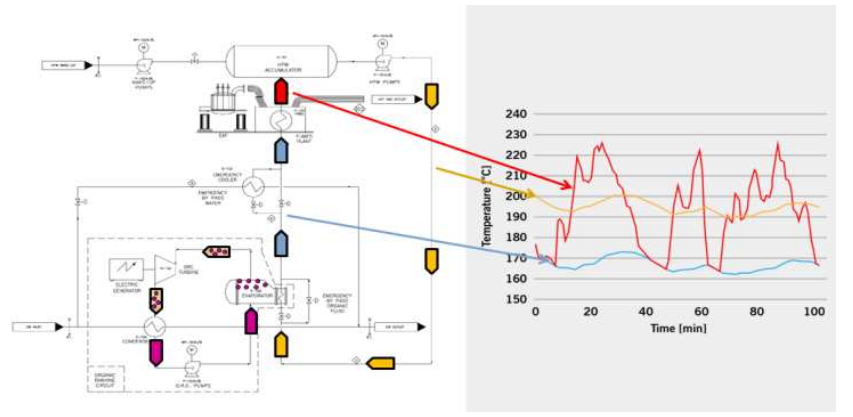

Figure 6 Performance of the Thermal Stabilizer Unit

The Thermal Stabilizer Unit works in synergy with the ORC system, in fact the heat storage function of the TSU is managed by a control system that evaluates the energy required by the ORC and the energy entering the TSU. The introduction of a heat recovery system affects also the water requirement of the evaporative tower. In fact, the sizing of the evaporative tower and its components is not more based on the peak thermal power, but it is based on the average thermal power. This change in the design principle leads to a reduction of about $40 \%$ of the water consumption of the evaporative tower. Thus, a further reduction of the operative costs is added.

\section{RESULTS AND DISCUSSION}

\subsection{First Step Towards Zero Energy FTP: The Case of ABS Steelmaking Plant}

Danieli has realized the first step towards Zero Energy FTP at ABS steelmaking plant (Italy) by installing $\mathrm{CHR}{ }^{\circledR}$ - Clean Heat Recovery. Before CHR installation, at ABS, EAF primary fumes (extracted from the fourth hole of the EAF roof) were cooled by water cooled panels and by a FDC (Forced Draft Cooler). Currently, the FDC has 
been replaced by a pressurized hot water recovery system. In this way use of FDC cooler fans is not necessary resulting in an additional electric energy saving. This solution is suitable in case of revamping in existing plants without significant layout modifications.

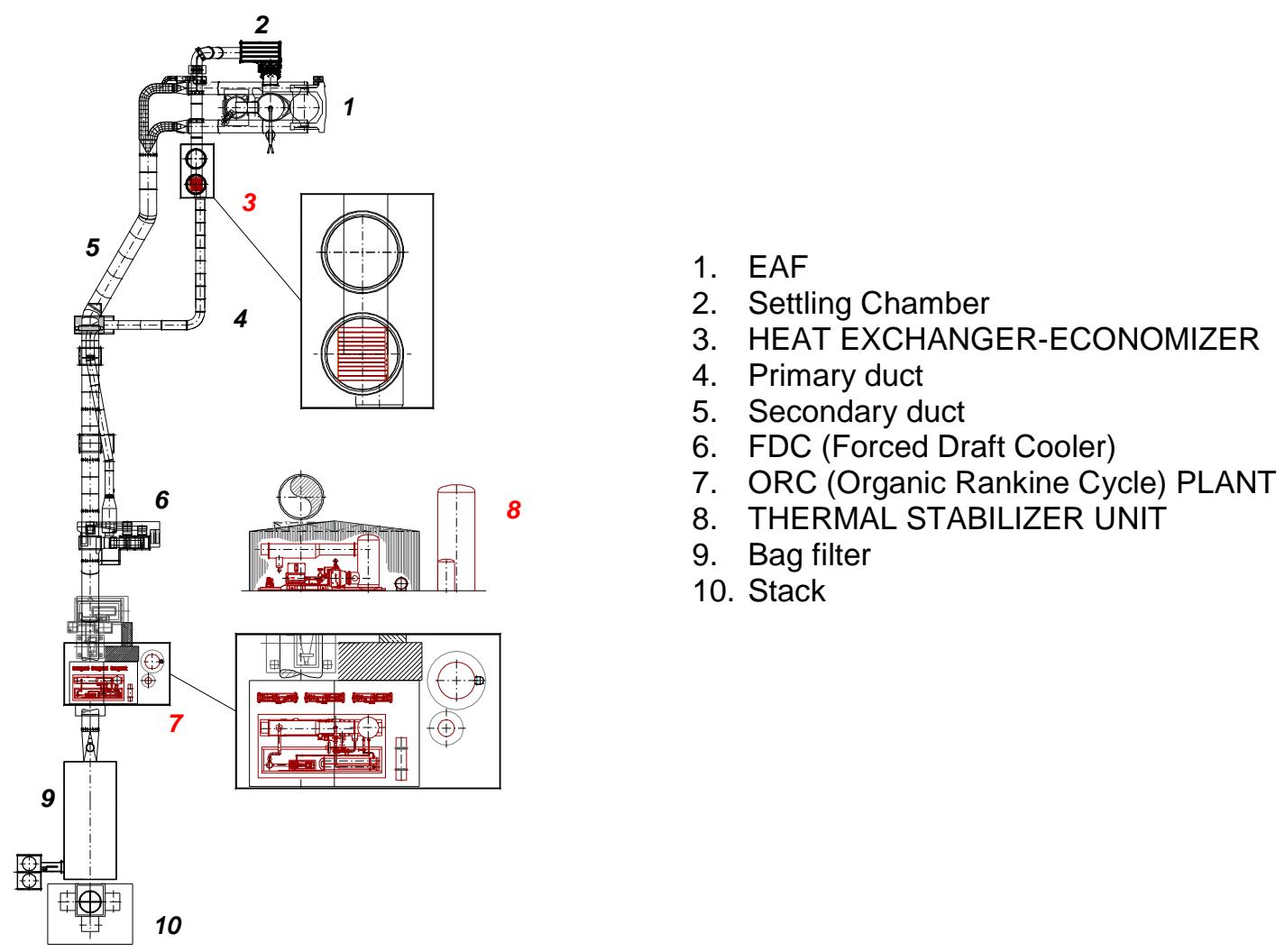

Figure 7: $\mathrm{CHR} \AA$ Layout - First step towards zero energy FTP

As previously explained, a zero-energy FTP requires a heat recovery system, a system to reduce the variability and to guarantee a continuous energy feeding during power-off phase and an energy conversion unit. As can be seen in Figure 7, CHR system installed in ABS plant has all the three required systems:

1. The heat recovery system is composed by a heat exchanger installed in the FTP after the WCDs;

2. The system that reduces the variability and guarantees a continuous energy feeding during power-off phase is the Thermal Stabilizer Unit;

3. The energy conversion system is the ORC Plant.

This plant has been started up on 17th October 2014 for the first time, and it has generated the first electrical power. The Human-Machine Interface (HMI) of the $\mathrm{CHR} \circledast$ is integrated in the $\mathrm{HMI}$ of the furnace, so all the process could be kept under control by the furnace operator.Figure 8(a) shows the operating conditions of the main components of the Hot Water circuit displayed in the HMI. While, the HMI in Figure $8(\mathrm{~b})$ shows the temperature of the Hot Water and the pressure trends during the startup of the CHR plant: starting from room temperatures, in about 4,5 hours the plant reaches nominal operating conditions. This trend shows the effect of Thermal Stabilizer on discontinuous Hot Water temperatures ("Heat exchanger outlet temperature"); it also shows pressure trend of the Hot Water plant. 

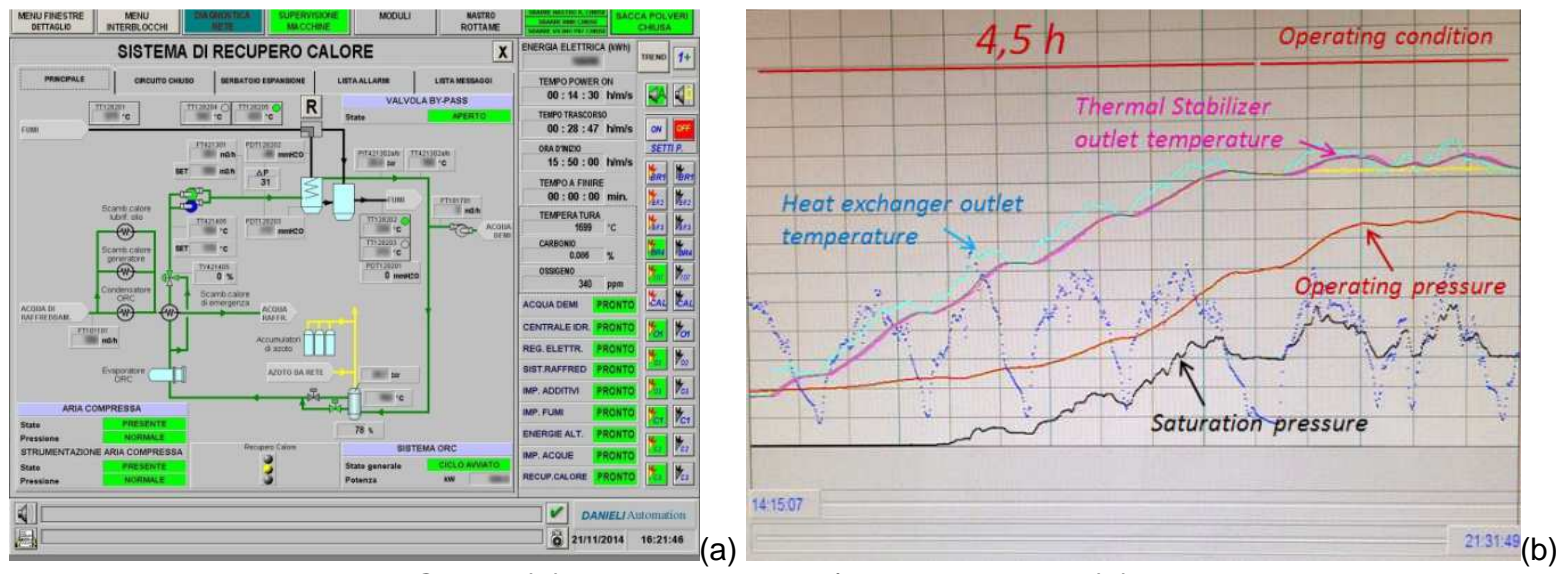

Figure 8: Hot water Circuit (a) and temperature/pressure trends (b) displayed on the HMI

In Figure 9 the Thermal Stabilizer Unit (a) and the ORC plant (b) installed at ABS are shown.
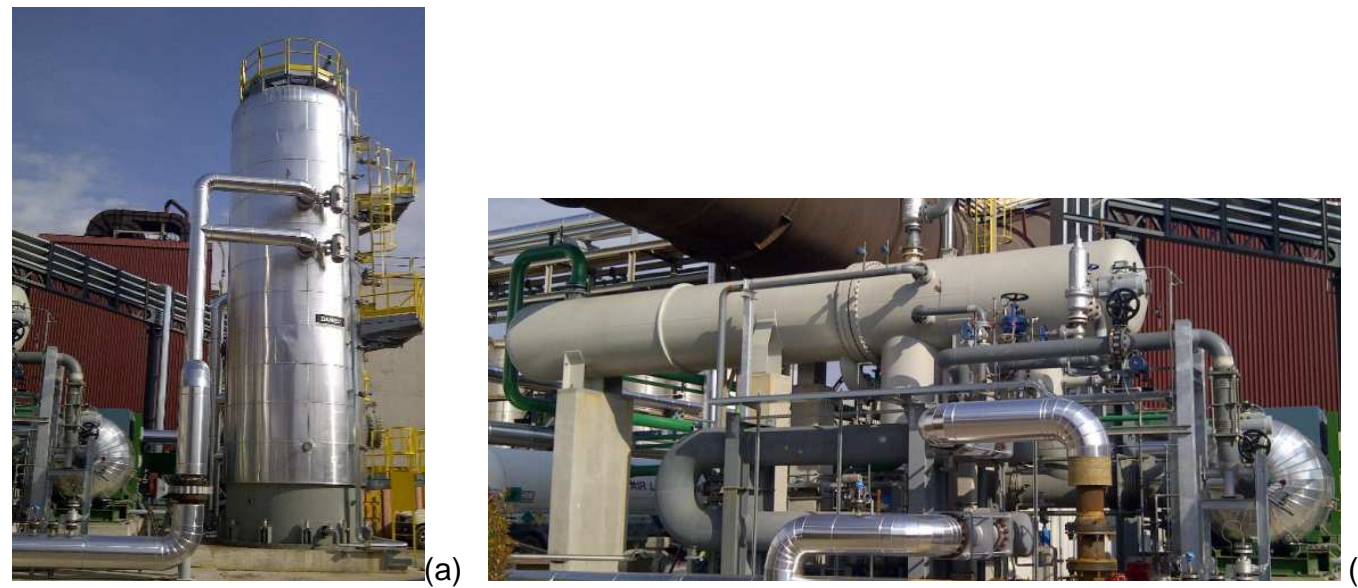

Figure 9:Thermal Stabilizer Unit (a) and ORC Plant (b)

In general, the quantity of recovered heat depends first of all on the size and melting profile of the EAF, which determine the design of the primary fume system. At ABS recovered thermal power reaches $5.5 \mathrm{MW}$. Table 1 shows the measured data during the commissioning:

Table 1: Commissioning Data

\begin{tabular}{|l|l|l|}
\hline $\begin{array}{l}\text { Measured data during the } \\
\text { commissioning }\end{array}$ & Measured & Design \\
\hline Hot water temperature max & $220^{\circ} \mathrm{C}$ & $265^{\circ} \mathrm{C}$ \\
\hline Max hot water pressure & $40 \mathrm{bar}(\mathrm{g})$ & $45 \mathrm{bar}(\mathrm{g})$ \\
\hline Hot water flow & $350 \mathrm{~m}^{3} / \mathrm{h}$ & $350 \mathrm{~m}^{3} / \mathrm{h}$ \\
\hline Max electrical power generated & $1032 \mathrm{~kW}$ & $1000 \mathrm{~kW}$ \\
\hline
\end{tabular}

In Figure 10 is shown a HMI screen photo that indicates the max power production reached with CHR plant installed at $\mathrm{ABS}$ (over $1 \mathrm{MW}$ of electric power): 


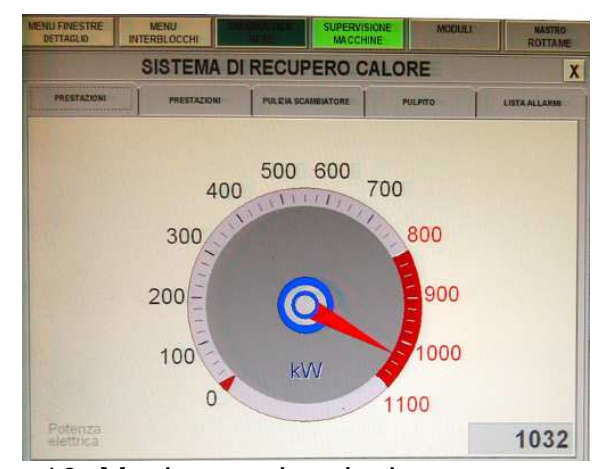

Figure 10: Maximum electrical power generation

Assuming a cost of electrical power to $0.07 € / \mathrm{kWh}$, the estimated annual saving is approx. 500,000 EUR, an amount surely sufficient to make attractive the additional cost of $\mathrm{CHR} \otimes$. The last raw of the Table 2 indicates the reduction of carbon dioxide emission, which is one of the most important green-house gas to keep under control. Recovering part of the waste heat gives also the opportunity the access to public financing. The amount of this financing for emissions reduction is variable country by country, and has a big contribution in the return of investment time. In green-field plants, energy recovered can reach values of $15-25 \mathrm{kWh} / \mathrm{t}$ of produced steel.

Table 2: Saving Balance

\begin{tabular}{|ll|}
\hline Power balance \\
\hline $\begin{array}{l}\text { Removed power from Waste heat } \\
\text { recovery }\end{array}$ & $5,5 \mathrm{MWt}$ \\
Nominal ORC power & $1 \mathrm{MWe}$ \\
\hline Energy balance & $7.200 .000 \mathrm{kWhe} / \mathrm{y}$ \\
\hline Energy recovered in 1 year \\
\hline Cost balance & $0.07 € / \mathrm{kWh}$ \\
\hline Energy cost (average) & $500.000 € / \mathrm{y}$ \\
Energy cost Recovered & $395.000 € / \mathrm{y}$ \\
White Certificates & \\
\hline Environmental Benefit & $2880 \mathrm{t} / \mathrm{y}$ \\
\hline CO2 saved &
\end{tabular}

\section{CONCLUSION}

The world of steel is always more interested in the new direction of saving and recovering. Steelmaking is an energy intensive industry which offers various opportunities to recover and waste heat recovery using hot water for electrical power generation via ORC turbines can well combine cooling efficiency, low maintenance and economical feasibility with environmental sustainability; following these new guidelines, the Clean Heat Recovery $\mathrm{CHR} \circledast$ project has been realized.

\section{BIBLIOGRAPHY}

1 Pardo N., Moya J.A., Vatopoulos K., Prospective scenarios on energy efficiency and CO2 emissions in the Iron \& Steel industry, Joint Research Centre, 2012.

2 Remus R., Aguado Monsonet M.A., Roudier S., Delgado Sancho L., Best Available Techniques (BAT) Reference Document for Iron and Steel Production, Industrial Emissions Directive 2010/75/EU (Integrated Pollution Prevention and Control); 2012.

3 G. Nardin, F. Dal Magro - "Scientific collaboration: Innovative devices for variance reduction of the thermal flux of waste gas characterized by high gradients of temperature" - University of Udine - Academic year 2011/2012. 